\title{
Photosynthetic Rate of Lettuce Cultivated on Floating Raft Hydroponic with Controlled Nutrient Solution
}

\author{
Lenni, Herry Suhardiyanto, Kudang Boro Seminar, Radite Praeko Agus Setiawan \\ Department of Mechanical and Bio-System Engineering, Bogor Agricultural University (IPB University), Bogor, Indonesia
}

ARTICLE INFO

Article history:

Received March 6, 2019

Received in revised form December 20, 2019

Accepted December 24, 2019

\section{KEYWORDS:}

photosynthetic rate,

lettuce plant,

control and monitoring system,

floating raft hydroponic,

ANN model

\begin{abstract}
Lettuce cultivations in tropical areas are often performed in open field of highlands. Such cultivation practices are often followed by soil erosion. To reduce soil erosion, it is important to shift lettuce cultivation areas to lowlands and to utilize hydroponic system. In such a hydroponic system, photosynthetic rate of the lettuce plants should be evaluated in order to formulate its relation with the cultivation conditions. This study aimed to evaluate the photosynthetic rate of lettuce plants cultivated in floating raft hydroponic system whose nutrient solution was controlled by a newly developed control and monitoring system. Furthermore, this paper presents an ANN model which consists of eight inputs (nutrient temperature, EC, pH, DO, and ORP, air temperature, air humidity, and PPFD) and one output (photosynthetic rate) to describe the relationship between these input parameters and the output parameter. It was noted that the ANN model predicted accurately the photosynthetic rate of lettuce leaves. The ANN model was useful for predicting the photosynthetic rate of lettuce plants cultivated in floating raft hydroponic system on tropical lowland.
\end{abstract}

\section{Introduction}

Plant growth is determined by the cell formation, requiring photosynthetic energy. Photosynthesis is one of carbon assimilation process that utilizes the light energy through the fixation of $\mathrm{CO}_{2}$ into glucose as chemical energy storage. The photosynthetic rate is important to study for improving the productivity of lettuce (Natr and Lawlor 2005; Fu et al. 2017; Ouyang et al. 2019; Zhou et al. 2019). The photosynthetic rate can be measured using photosynthetic rate meter. The rate of photosynthesis is determined by the main factors, namely visible light intensity, water availability, $\mathrm{CO}_{2}$ concentration in the air, and leaf chlorophyll content, as expressed in the equation of light reaction to convert energy into glucose through the photosynthesis (Rabinowitch 1951). In addition, some other factors also affect the photosynthetic rate, namely adequate temperature and nutrients.

Lettuce plants can be cultivated hydroponically in every season of the year in a greenhouse in subtropical climates (Nothmann 1977; Marrou et al. 2013). In tropical climates, lettuce plants can grow well in the highlands (Hakim et al. 2019). Hydroponic

\footnotetext{
* Corresponding Author

E-mail Address: herrysuhardiyanto@ipb.ac.id
}

technology allows increased growth of 95\% as compared to conventional cultivation in soil that require large area and crop rotation, thus requiring crop rotation to restore soil nutrient availability for plants. Hydroponic technology solves this problem by continuously supplying the nutrients according to the needs of plants (Norman et al. 2019).

To reduce the risk of soil erosion and pesticide contamination, the cultivation of lettuce plants in high open land needs to be reduced. As an alternative to this method, the cultivation of lettuce in hydroponics in the lowland area has an advantage in implementation of pesticide-free cultivation (Sumarni et al. 2013a, 2013b, 2013c; Sumarni et al. 2016). With the use of greenhouses, rain water that drops can be more easily collected and filtered as rain water harvesting efforts (Lee et al. 2008; Moon et al. 2012). Hydroponically cultivated lettuce plant in greenhouse on tropical lowland has the advantages of fulfilling the light requirement with high quality and productivity, however also having disadvantage of high temperature condition in the root zone of the plant (Hatfield et al. 2011; Wiebbecke et al. 2012; Hatfield and Prueger 2015). Therefore, hydroponic technology for lettuce cultivation in greenhouse needs to be developed for tropical lowland climates. 
Instead of cooling the whole air inside the greenhouse, cooling the root zone has been developed as energy-efficient cooling system for greenhouses (Suhardiyanto and Matsuoka 1992; Suhardiyanto and Matsuoka 1994; Suhardiyanto 2009). Nutrient solutions have specific heat higher than the air, therefore the cooling of nutrient solution in hydroponic system has the possibility to become energy-efficient cooling system for plant cultivation using hydroponic system in tropical areas. The root zone cooling system has been used successfully to cool the root zone (Arancon et al. 2015).

The experiment on zone cooling for plant root has been performed on the aeroponic system for potato (Sumarni et al. 2013) and using floating raft hydroponic for onion (Niam et al. 2017), which produces good plant growth. Cultivation of plants using floating raft hydroponic technology can be advantageous, although it requires energy for cooling. The root zone cooling requires enormous electrical energy. However, it can be solved by controlling the temperature automatically.

The relationship between these factors and photosynthetic rate has been examined through various approaches, i.e. induction approach of drawing conclusion from experiments and modelling approach using Artificial Neural Network (ANN) (Morimoto et al. 1995). Studies have successfully used ANN's model to explain the relationship between among parameters that are very complex and difficult to express with certain equations (Morimoto et al. 1995; Tamrin et al. 2005). ANN model was developed from the basic human brain model with generalization and learning capabilities. ANN can be used as universal function approach to represent the main function and amount of nonlinear terms (Grzersiak and Ufnalski 2004). The photosynthetic rate model for lettuce cultivated in floating raft hydroponic system with nutrients controlled using control and monitoring systems inside greenhouse on tropical lowland needs to be developed against the factors of cultivation conditions for operational guidance base and further development.

\section{Materials and Methods}

\subsection{Experiment}

This study includes experiment on lettuce cultivation in floating raft hydroponic system whose nutrient was controlled using control and monitoring systems developed previously. The plant used was
Grand Rapid var. green lettuce. Other materials used were water, fertilizer for hydroponically cultivated vegetable plants ( $\mathrm{AB} \mathrm{Mix})$, nitric acid $\left(\mathrm{HNO}_{3}\right)$, potassium hydroxide $(\mathrm{KOH})$, and citric acid $\left(\mathrm{C}_{6} \mathrm{H}_{8} \mathrm{O}_{7}\right)$. Instruments used in this study included LI-COR 6800-XT photosynthetic rate meter, controlled and monitoring systems, laptop, chiller, aerator pumps, and two systems of floating raft hydroponic with 1.3 x 6.1 x $0.28 \mathrm{~m}$ size. The experiment was conducted in the modified standard peak greenhouse type of Siswadhi Soepardjo field laboratory, Department of Mechanical Engineering and Biosystem, Faculty of Agricultural Engineering and Technology, IPB University, Leuwikopo, Dramaga, Bogor. This study was performed from October to December, 2019.

\subsection{Root Zone Parameter Measurement}

Temperature, EC, pH, DO, ORP values of the nutrient solution were measured and recorded using the control and monitoring system developed in the previous study. These parameters were used to represent root zone conditions. Measurements were performed within 10-second time interval, starting from 19 to 21 November, 2019. The measurement results can be read in an LCD. Sensors were connected with Arduino Mega microcontroller 2560. Recorded values on LCD that can be read directly were used as the measured root zone parameter data. However, for the purposes of ease storage and processing, data was kept on micro SD card. When value of the parameter is outside the specified limit, then relay in the control and monitoring system activate the relevant actuator.

\subsection{Photosynthetic Rate Measurement}

Photosynthetic rate measurement was carried also from 19 to 21 November, 2019. The measurement was conducted by using LI-COR 6800 XT photosynthetic rate meter (Figure 1). The instrument was equipped with leaf chamber, gas analyzers, flow control, valve system, and fluorometer devices. The LI-6800 controls environmental conditions in the chamber for the duration of a measurement. By controlling chamber conditions at the setpoints, the photosynthetic response to changes in intercellular $\mathrm{CO}_{2}$ concentration is not confounded by other independent variables. Flow rate was maintained precisely, reducing the moment-to-moment variation that impacts the calculated carbon assimilation rate. The leaves were illuminated with constant irradiation, ensuring a biochemical reaction rate relies on consistent light 
in most areas of the leaf covered. Output of the measurement was $\mathrm{CO}_{2}$ assimilation rate.

\subsection{ANN-Based Photosynthetic Rate Modelling}

The advantages of the artificial neural network (ANN)-modelling are that it is a robust estimation for non-linear biological processes. In this research, an ANN model-based simulation is proposed to estimate the $\mathrm{CO}_{2}$ assimilation rate of lettuce plants cultivated in floating raft hydroponic system whose nutrient solution was controlled using the control and monitoring systems. Same model is proposed also for that of uncontrolled. The ANN model proposed in this research consisted of input layer, hidden layer, and output layer (Figure 2). The input parameters are as follows: temperature, EC, DO, pH, and ORP nutrient solution, air temperature, air humidity, and photon flux density of photosynthesis of the lettuce plants. The output variable is the $\mathrm{CO}_{2}$ assimilation rate of lettuce plants.

The ANN model was developed using datasets collected from the cultivation of lettuce in two floating raft hydroponic systems. A total of 230 datasets were used to develop the ANN models, that were 115 datasets for each hydroponic system. The 115 datasets were divided randomly into data for training (77 datasets) and data for validation (38 datasets). The ANN model was developed using the data for training. The weights were used to represent the connection between the input parameters and the output parameter. The initial values of weight were generated randomly. An adjustment was performed by training process using sample data through backpropagation neural network. The developed

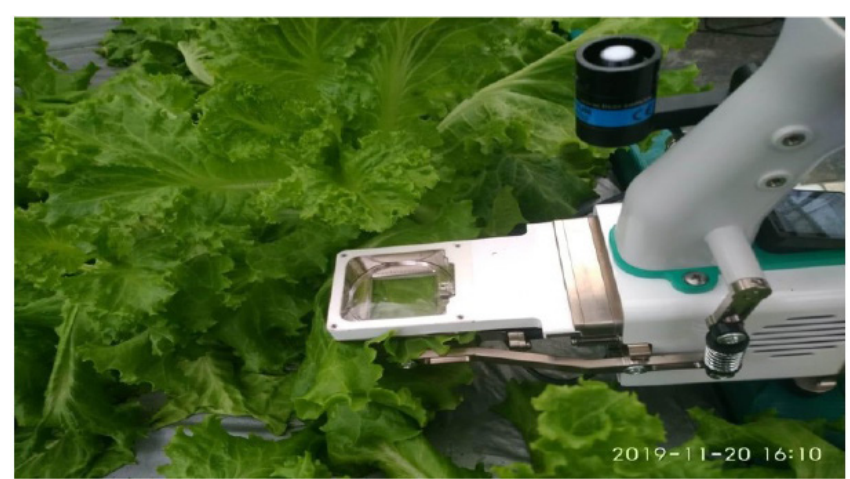

Figure 1. Photosynthetic rate measurement using LI-COR 6800 XT photosynthetic rate meter (www.licor. com/env)

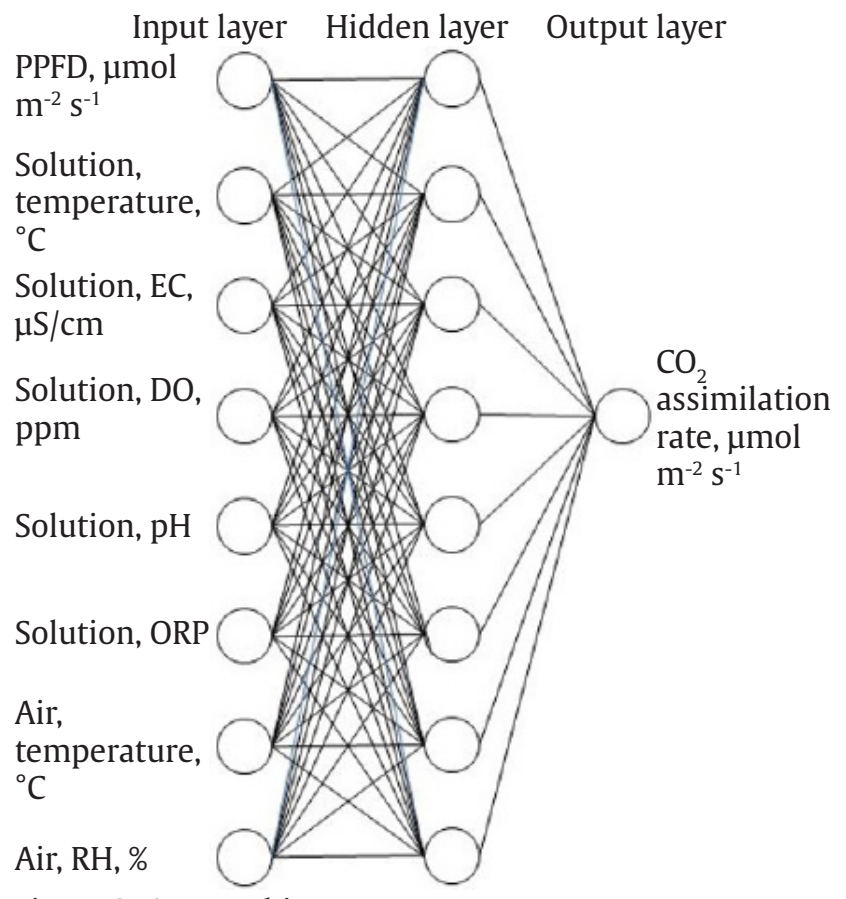

Figure 2. ANN architecture

model then was validated using the empirical data for validation. Coefficient of determination was used to evaluate the model's performance.

\section{Results}

\subsection{Statistical Analysis}

The relation between $\mathrm{CO}_{2}$ assimilation rates of lettuce plants cultivated in controlled and uncontrolled nutrient solution of floating raft hydroponic and PPFD ranges are presented in Figure 3. Results of analysis of variance on $\mathrm{CO}_{2}$ assimilation rate of the lettuce plants are listed in Table 1 . Statistical analysis was performed in this study to examine the influence of different treatment levels and PPFD ranges on $\mathrm{CO}_{2}$ assimilation rate. The analysis used Factorial Completely Randomized Design 2 x 5, namely: 2 treatments (controlled and uncontrolled) and 5 PPFD ranges $(0-100,101-200,201-300,301-$ 400, and 401-500). Each treatment combination had different replications. Significant difference among treatment combinations were evaluated using Tukey Multiple Comparison Test. Summary of the relation between average $\mathrm{CO}_{2}$ assimilation rate of lettuce plants and PPFD ranges are listed in Table 2. 


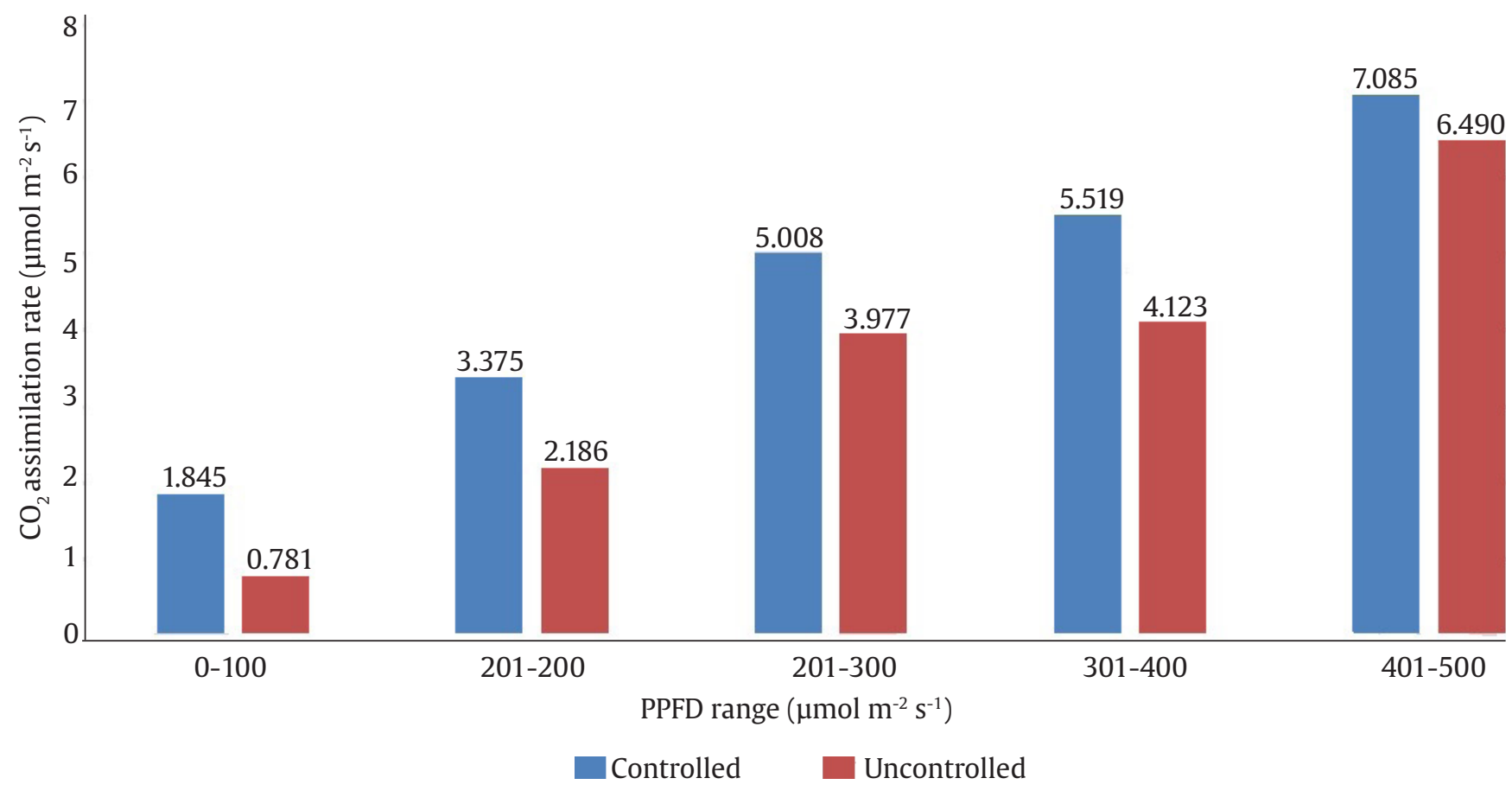

Figure 3. Relation between $\mathrm{CO}_{2}$ assimilation rate of lettuce plants cultivated in floating raft hydroponic and PPFD ranges

Table 1. Two factors analysis of variance on $\mathrm{CO}_{2}$ assimilation rate $\left(\mu \mathrm{mol} \mathrm{m} \mathrm{m}^{-2}\right)$ of the lettuce plants

\begin{tabular}{lcccc}
\hline Source of diversity & Sum square $(\mathrm{SS})$ & Degree of freedom $(\mathrm{df})$ & Mean square $(\mathrm{KT})$ & $\mathrm{p}$-value \\
\hline Treatment & 52.71 & 1 & 52.71 & 0.0001 \\
PPFD range $\left(\mu \mathrm{mol} \mathrm{m}^{-2} \mathrm{~s}^{-1}\right)$ & 756.6 & 4 & 189.1 & 0.0001 \\
Treatment*PPFD range & 2.626 & 4 & 0.6565 & 0.636 \\
Residuals & 224.6 & 218 & 1.03 & \\
Total & 1036.536 & 227 & & \\
\hline
\end{tabular}

*Significance on $5 \%$ degree of confidence

Table 2. Summary of the relation between average $\mathrm{CO}_{2}$ assimilation rate $\left(\mu \mathrm{mol} \mathrm{m} \mathrm{m}^{-2} \mathrm{~s}^{-1}\right.$ of lettuce plants and PPFD ranges $\left(\mu \mathrm{mol} \mathrm{m} \mathrm{m}^{-2} \mathrm{~s}^{-1}\right)$

\begin{tabular}{llcccc}
\hline \multirow{2}{*}{$\begin{array}{l}\text { PPFD range } \\
\left(\mu \mathrm{mol} \mathrm{m} \mathrm{m}^{-2} \mathrm{~s}-1\right)\end{array}$} & Treatment & \multicolumn{3}{c}{$\mathrm{CO}_{2}$ assimilation rate } \\
\cline { 3 - 5 } & & Mean & Standard deviation & Coefficient of variation & Number of sample \\
\hline $0-100$ & Controlled & $1.845^{\mathrm{a}}$ & 0.365 & 19.785 & 29 \\
\multirow{2}{*}{$101-200$} & Uncontrolled & $0.781^{\mathrm{b}}$ & 0.494 & 63.223 & 39 \\
& Controlled & $3.375^{\mathrm{cf}}$ & 1.115 & 33.020 & 38 \\
\multirow{2}{*}{$201-300$} & Uncontrolled & $2.186^{\mathrm{a}}$ & 0.750 & 34.324 & 25 \\
& Controlled & $5.008^{\mathrm{def}}$ & 1.129 & 22.538 & 25 \\
\multirow{3}{*}{$301-400$} & Uncontrolled & $3.977^{\mathrm{cdf}}$ & 1.065 & 26.776 & 10 \\
& Controlled & $5.519^{\mathrm{eg}}$ & 1.207 & 21.876 & 16 \\
\multirow{2}{*}{$401-500$} & Uncontrolled & $4.123^{\mathrm{f}}$ & 0.951 & 23.066 & 13 \\
& Controlled & $7.085^{\mathrm{h}}$ & 0.756 & 30.678 & 20 \\
\hline \multirow{2}{*}{ Total } & Uncontrolled & $6.490^{\mathrm{gh}}$ & 2.004 & & 115 \\
\hline
\end{tabular}

Values in columns followed by the same letter are not significant (p-value $<0.05$, Tukey Multiple Comparison Test)

3.2. ANN Model Performance for Predicting Rate The performance of ANN model in predicting the photosynthetic rate of lettuce cultivated in these hydroponic systems are indicated by results of validation of the developed model. Result of validation on the developed ANN model for lettuce cultivation without control and monitoring system is presented in Figure 4 and that of controlled system is presented in Figure 5. 


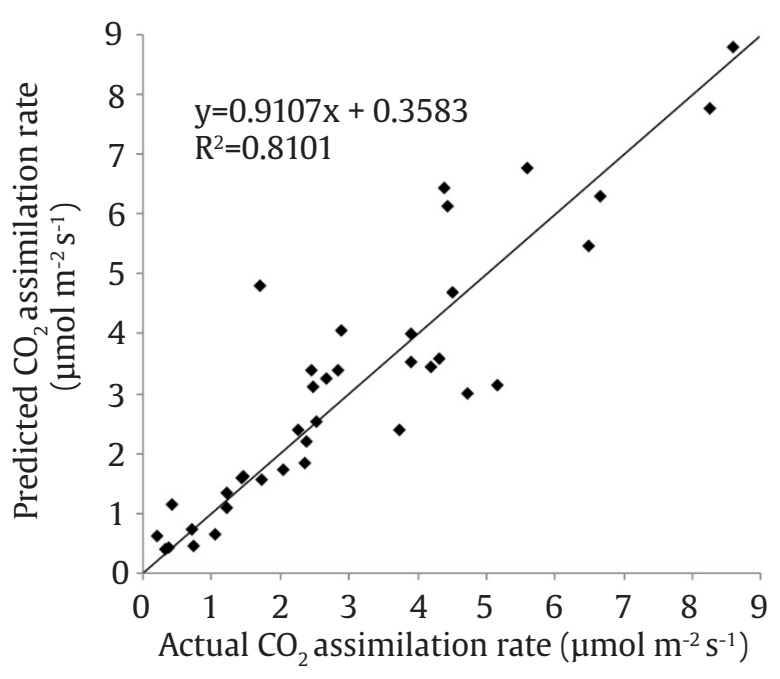

Figure 4. Validation results of ANN model for predicting $\mathrm{CO}_{2}$ assimilation rate of lettuce plants cultivated on floating raft hydroponic with uncontrolled nutrient solution

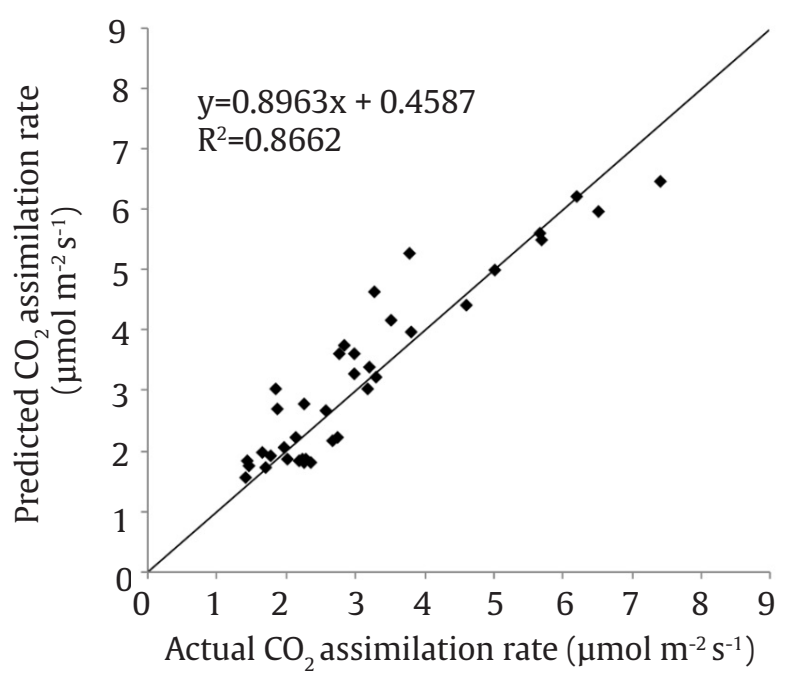

Figure 5. Validation results of ANN model for predicting $\mathrm{CO}_{2}$ assimilation rate of lettuce plants cultivated on floating raft hydroponic whose nutrient solution controlled using control and monitoring system

\section{Discussion}

Results showed that higher PPFD resulted in higher $\mathrm{CO}_{2}$ assimilation rate. Furthermore, it was noted that $\mathrm{CO}_{2}$ assimilation rate of lettuce cultivated in controlled system had higher $\mathrm{CO}_{2}$ assimilation rate as compared to that of uncontrolled system. As shown in Table 1, there were significant effect on each treatment at a significant level of $5 \%$. However, interactions between treatments did not have different effects at the 5\% level. Tukey Multiple Comparison Test was used to determine the difference among treatment interactions. Table 2 also shows that 201-300 and 401-500 PPFD range had no significant difference among treatments using controlled and uncontrolled system on $5 \%$ degree of confidence. Other treatments showed significant differences either on PPFD ranges or controlled and uncontrolled system. Moreover, coefficient of variance for uncontrolled system tended to be higher than that of controlled system.

As shown in Figures 4 and 5, the slope and intercept of the regression lines between among the predicted $\mathrm{CO}_{2}$ assimilation rates and the actual $\mathrm{CO}_{2}$ assimilation rates explain how fit the prediction to that of actual values. The regression lines had $\mathrm{R}^{2}$ values of 0.8101 and 0.8662 for lettuce plants without and with control system, respectively. It has been known that the relationship is complex and very difficult to be explained using mathematical models. Dealing with the complexity of ill-defined processes such as the photosynthesis, ANN model performed well in estimating the parameter. ANN models predicted the $\mathrm{CO}_{2}$ assimilation rate in very good accuracy with MSE value of 0.9163 and 0.3242 for lettuce plants without and with control system, respectively. The RMSE value was 0.9572 and 0.5694 for lettuce plants without and with control system, respectively. Basically, ANN modelling is computation process that produces a model to represent the nature correlation of the data for training step in the modelling. The modelling treats the correlation between input parameters and the output like a black box that receives input and gives output. It was noted that the ANN modelling has the capability to learn and recognize the pattern of $\mathrm{CO}_{2}$ assimilation rate data which were empirical without any physical consideration normally used as the basis for mathematical formulation. The ANN model was robust enough in non-linear biological modelling to examine the complex correlation between input parameters and the $\mathrm{CO}_{2}$ assimilation rate of lettuce plants. Therefore, the contribution of this research was the ANN model that is useful in explaining such complex correlation.

\section{Conclusion}

The relations between $\mathrm{CO}_{2}$ assimilation rates of lettuce plants cultivated in floating raft hydroponic systems whose nutrient was uncontrolled and controlled using control and monitoring systems and PPFD ranges were examined. There were significant differences on average photosynthetic rate between $\mathrm{CO}_{2}$ assimilation rates of lettuce plants in these two hydroponic systems. The ANN model predicted the $\mathrm{CO}_{2}$ assimilation rate of lettuce cultivated in these two hydroponic systems with quite good accuracy. The ANN was useful for identifying the photosynthetic rate of lettuce cultivated in the floating raft hydroponic systems. 


\section{References}

Arancon N et al. 2015. Effects of coconut husk and sphagnum moss-based media on growth and yield of Romaine and Buttercrunch lettuce (Lactuca sativa) in a noncirculating hydroponics system. Journal of Plant Nutrition 38:1218-1230. DOI:10.1080/01904167.201 4.983117

Fu Y et al. 2017. Interaction effects of light intensity and nitrogen concentration on growth, photosynthetic characteristics and quality of lettuce (Lactuca sativa L. Var. youmaicai). Scientia Horticulturae 214:51-57.

Grzesiak LM, Ufnalski B. 2004. Neural stator flux estimator with dynamical signal preprocessing. In: 2004 IEEE Africon: $7^{\text {th }}$ Africon Conference in Africa. Gaborone: IEEE. pp. 1137-1142.

Hakim MAR et al. 2019. Growth and production of two varieties of lettuce at various levels of shade by hydoponic methods. J Agro complex 3:15-23.

Hatfield JL et al. 2011. Climate impacts on agriculture: implications for crop production. J Agron 103:351-370.

Hatfield JL, Preuger. 2015. Temperature extremes: effect on plant growth and development. Weather and climate extremes 10:4-10.

Lee BJ et al. 2008. Evaluation of the qualities of rainwater collected from the top of vinyl house. Water wastewater 22:315-322.

Marrou H et al. 2013. Productivity and radiation use efficiency of lettuces grown in the partial shade of photovoltaic panels. European Journal Agronomy 44:54-66.

Moon S et al. 2012. Quality of harvested rainwater in artificial recharge site on jeju volcanic island, Korea. Journal of hydrology 414:268-277.

Morimoto T et al. 1995. Optimal control of physiological processes of plants in a green plant factory. Control Engineering Practice 3:505-511.

Natr L, Lawlor DW. 2005. Photosynthetic Plant Productivity. In: Pessarakli M (Eds.). Handbook of Photosynthesis, 2nd edition. Boca Raton: CRC Press. pp. 501-522.

Niam et al. 2017. Simulation of temperature distribution on the planting hole of floating hydroponic for shallot production in tropical lowland. Jurnal Keteknikan Pertanian 5:235-244.

Norman Q et al. 2019. The effects of vermicompost tea on the growth and yield of lettuce and tomato in a non-circulating hydroponics system. Journal of plant nutrition 42:2447-2458. DOI:10.1080/01904167.2019 .1655049
Nothmann J. 1977. Effects pf soil temperature on head development of cos lettuce. Scientia Horticulturae 7:97-105.

Ouyang Z et al. 2019. Effects of different concentrations of dissolved oxygen or temperatures on the growth, photosynthesis, yield and quality of lettuce. Agriculture Water Management 228:1-8. DOI:10.1016/j. agwat.2019.105896

Rabinowitch E. 1951. Photosynthesis. Annual Review of Physical Chemistry 2:361-382.

Suhardiyanto H, Matsuoka T. 1992. Studies on a zone cooling system in a greenhouse (2). Evaluation of a system for microclimate modification in a plastic greenhouse during hot weather. Environment Control in Biology 30:143-151.

Suhardiyanto H, Matsuoka T. 1994. Uniformity of cool air discharge along a perforated tube for zone cooling in a greenhouse. Environment Control in Biology 32:9-16.

Suhardiyanto H. 2009. Teknologi Rumah Tanaman untuk Iklim Tropika Basah. Bogor: IPB Press.

Sumarni E et al. 2013. Seed potato production using aeroponics system with zone cooling in wet tropical lowlands. Acta Horticulturae 1011:141-145.

Sumarni et al. 2013a. Application of root zone cooling in potato seed production using wet tropical aeroponik. J Agron Indonesia 41:154-159.

Sumarni et al. 2013b. Heat transfer in aeroponic chamber with zone cooling application. Journal of Biophysics 9:8-15.

Sumarni et al. 2013c. Zone cooling application in the potato aeroponic system in the wet tropical medium plains. Journal of Agricultural Engineering 1:99-106.

Sumarni et al. 2016. Potato seed production in aeroponics system and root zone coolingat different pump pressures in the lowlands. JAgron Indonesia 44:299-305.

Tamrin et al. 2005. A model of vegetative stage of baby cucumber using artificial neural network. Journal of Agricultural Engineering 19:1-10.

Wiebbecke CF et al. 2012. Day temperature influences the male-sterile locus in soybean. Crop Sci 52:1503-1510.

Zhou J et al. 2019. Growth, photosynthesis, and nutrient uptake at different light intensities and temperatures in lettuce. HortScience 54:1925-1933. 